\title{
Symptomatic form of hemophilia B in female carriers
}

INSERM

\section{Source}

INSERM. (1999). Orphanet: an online rare disease and orphan drug data base.

Symptomatic form of hemophilia B in female carriers. ORPHA:177929

Symptomatic hemophilia B in female carriers is a form of hemophilia B (see this term)

that manifests in some women with mutations in the F9 gene (Xq28), encoding coagulation factor IX. 